Saudi Journal of Business and Management Studies Abbreviated Key Title: Saudi J Bus Manag Stud ISSN 2415-6663 (Print) |ISSN 2415-6671 (Online) Scholars Middle East Publishers, Dubai, United Arab Emirates Journal homepage: https://saudijournals.com

Original Research Article

\title{
Complications of SME Sector Due to the Outbreak of COVID-19 and Projections on it: A Study on Cumilla District
}

\author{
Rashed Ahmed $^{1 *}$, Mst. Noiyan Tara ${ }^{1}$, Ayesha Aktar ${ }^{1}$, S. M. Atiquzzaman Mulla ${ }^{2}$, Dr. Md. Elias Hossain ${ }^{3}$ \\ ${ }^{1}$ Lecturer, Department of Economics, Comilla University Bangladesh \\ ${ }^{2}$ Student, Department of Economics, Comilla University Bangladesh \\ ${ }^{3}$ Professor, Department of Economics, Rajshahi University Bangladesh
}

DOI: $10.36348 /$ sjbms.2022.v07i01.001 | Received: 11.12.2021 | Accepted: 07.01.2022 | Published: 10.01 .2022

*Corresponding author: Rashed Ahmed

Lecturer, Department of Economics, Comilla University Bangladesh

\section{Abstract}

Most of the economic sectors of the world are affected by the unembellished outspread of Covid-19. The economy of Bangladesh could not go beyond its adverse effect. This study tries to determine the complications of the SME sector of Cumilla district due to the outbreak of the Covid-19 pandemic situation and to indicate some strategic choices to adapt to the hostile Covid-19 situation. Setting three possible strategies of the SMEs to adapt adverse Covid-19 conditions, the binary logistic model is used in this study and found that asset level and labor force management have a significant impact on the decision making of the SMEs. Kendall's W shows that 'a decrease in revenue earnings' is the most pressing constraint faced by the SMEs during the period. To survive in the market, individual attempts of the SMEs may not be fruitful at all, stakeholders should come forward soon.

Keywords: SMEs, Covid-19, Binary Logit Model, Operation Cost Cut, Staff Cut, Cumilla.

Copyright (0) 2022 The Author(s): This is an open-access article distributed under the terms of the Creative Commons Attribution 4.0 International License (CC BY-NC 4.0) which permits unrestricted use, distribution, and reproduction in any medium for non-commercial use provided the original author and source are credited.

\section{INTRODUCTION}

Bangladesh has been observing a substantial GDP growth rate compared to other developing countries alike but from the middle of the $1^{\text {st }}$ quarter of the year 2020, the country, as well as the world, is in great trouble because of the outbreak of the pandemic of COVID-19. But it is our concern now that the growth rate may fall tremendously to the upcoming years because of strict closure of the whole firm-level activities. Small and medium scale enterprises (SMEs) also cannot get rid of it. For countries like ours, small businesses are already suffering from various problems that are now likely to be burning from the pandemic and trying to survive. SME foundation report of 2018 listed that SMEs of Bangladesh contribute to employment for 7.8 million people directly and provide a livelihood for 31.2 million (cited in Light-Castle Partners \& Sheba.xyz, 2020). Therefore, bearing in mind the potentiality of the SME sector and its present breakdown resulting from the outbreak of pandemic this study is taken into deliberation to sort out.
According to a report published by the world trade organization (2017), SMEs occupy more than $90 \%$ of the business enterprises of developing countries. To accelerate industrialization and employment creation, SMEs of Bangladesh is playing an important role. As a result of the severe outbreak of Covid-19 in Bangladesh, our government was compelled to continue a strict lockdown for more than two months and partial closure for five months. Except for grocery, almost all other small and medium scale businesses and industry sectors had remained completely laid off and thus causing a pronounced problem for those people who are directly involved with it. Beside the education and health sectors, industry and commerce also affected intensely and this study is mainly focusing on the adverse effect on small and medium scale enterprises (SMEs) and small businesses sectors as well. $28 \%$ of SMEs have seen revenue drop by at least $50 \%$, while $52 \%$ of SMEs have drooped over their businesses generating no revenue at all (Light-Castle Partners \& Sheba.xyz, 2020). Considering the important issues and 
Rashed Ahmed et al., Saudi J Bus Manag Stud, Jan, 2022; 7(1): 1-10

SMEs being a thirst sector of our economy needs a closer look for stimulating progress.

\section{LITERATURE REVIEW}

Several reports, newspapers, research papers, and online resources have been reviewed broadly to get an idea about the contemporaneous situation, severity, and waves, impacts on economic activity, and earlier findings of the researcher. In addition, ongoing problems of the market \& business sector, methodological issues, and prospects of the small business sectors are taken into consideration from research works.

\subsection{Specific Review of Related Works}

A study conducted in the USA over 5800 small businesses by Bartik et al. (2020) reported that $41.3 \%$ of businesses were temporarily closed because of Covid-19. A far smaller number-1.8\% - reported that they were permanently closed because of the pandemic. By contrast, only $1.3 \%$ reported that they were temporarily closed for other reasons; $55.5 \%$ reported that they were still operational. They found that the risk of closure was negatively associated with the expected length of the crisis. Surveying on 13 countries, Adian (et al., 2020) states that firms are mostly affected in multiple dimensions: particularly small and medium firms are more affected due to sales shrink and cash drain faster than large firms. The Covid-19 outbreaks pose that a market may be replaced by another e.g., combustion engines for electric or physical teaching for online teaching (Donthu and Gustafsson, 2020), homes are transitioning into make-shift offices, classrooms, broadcast studios, gyms, places of worship, and doctors' offices.

Personal computers became the gateway to the majority of human interaction and socializing beyond immediate family members (Kirk and Rifkin, 2020). Seetharam (2020) recognized that the business model shift due to Covid 19. Firms or industries produce technological products or services. Those who can continue their business functions while those products are labor-intensive tend to close or minimize their operation. Sheth (2020) innovate that the consumer behavior changed due to COVID 19 and increased the technology in buying and selling. Social media such as Facebook, WhatsApp, Instagram, Twitter, and Zoom are popular platforms for purchasing goods and services. So this changing consumer behavior also affects the SME sector badly. But in the case of the industry and business sector particularly in the SME sector, it is quite impossible to arrange activities virtually where labor needs to meet machinery to continue production and sales matter as well. Now, the question arises how the SME sector will face this ongoing pandemic situation? The answer is to adapt and adjust to the pandemic situation prudently. So our SME sector needs to adjust to the pandemic situation to overcome the survival problem.

\subsection{Gaps of Earlier Researches}

There is a little number of researches in this field as it is a concurrent issue and most of the works are done with secondary data. In Bangladesh, focusing on the SME sector the number of research works is still limited. Again, there is no precise work in the Cumilla region on the SME sector. Considering these issues, the study is an attempt to accomplish and sought after the objectives taken in this study.

\section{EXTENT AND SEVERITY OF COVID- 19 IN BANGLADESH.}

Bangladesh is a large country as to its population size and several regions of our country are densely populated. For the most part, the city areas are exceedingly populated specially Dhaka. The first Covid-19 case was found in Dhaka and then time Covid-19 peoples were mainly infected from outside and then blowout over the countrymen also. It has been said that Bangladesh is facing $1^{\text {st }}$ wave of the Covid-19 pandemic and it is unknown to all whether the condition will be good or bad for the upcoming days. Between 8 March and 07 September 2020, according to the Institute of Epidemiology, Disease Control and Research (IEDCR) there were 327,359 COVID-19 confirmed cases by rRT-PCR, including 4,516 related deaths (IFR1.38\%) $\left[^{1}\right]$, (MMWU [2], 07 Sep., 2020). Although the number of infected people and death rate is decreasing, it is still not safe for movement and keeps functioning of every economic activity because of the possibility of infection from it. Hence, most of the government and private offices, firms and industries, have been functioning with a limited hour of doings and to a restricted extent following the rules of basic hygiene.

At the very beginning of spreading Covid-19 in Bangladesh, Cumilla was prone to be affected with Covid-19 being located beside Narayanganj, which was the hotspot of Covid-19 after Dhaka. After founding the existence of Covid-19 in Bangladesh, Dhaka, Narayanganj, Gazipur, and then Cumilla was severely affected by it and the business sector of these locations is badly hindered because of it. The outbreak of Covid19 most harms particularly the small and medium scale enterprises of these locations. It is seen that comparing other districts of the Chittagong division, the number of Covid-19 confirmed cases in Cumilla district is much higher than other districts of this division (Coronavirus COVID-19 Dashboard, 2020). Hence, it is a burning issue for the health \& survival condition and the economic activities of this region, whether operational or closed or adapt to the ongoing situation.

\footnotetext{
${ }^{1}$ IFR refers to 'Infection Fatality Ratio' which can describe the true severity of a disease ${ }^{2}$ Morbidity and Mortality Weekly Update (MMWU)
} 


\subsection{Research Questions}

Considering the above discussions about the question of economic impacts on the SME sector, unemployment, blocking supply chain issues, falling demand of several items, and other general topics, some research questions do arise which needs a quick response:

a) How can the SME sector adapt economic disturbances due to the Covid-19 outbreak?

b) What are the causes that badly affect the SME sector in the pandemic period?

c) What will be the possible expectations and solutions to get rid out of it?

\subsection{Objectives of the Study}

Bearing in mind the above questions, this study is an attempt to discover the adverse impact on the SME sector due to the Covid-19 outbreak in Bangladesh. Hence, the following objectives are as follows besides the main objectives.

a) To find the way for the SME sector to adapt economic disturbances that occurred by the Covid19 outbreak.

b) To find out the most relevant factors that impede the SME sector badly.

c) To identify the expected \& possible ways to overcome this economic hazard.

\section{METHODOLOGY}

\subsection{Sampling Design and Data Collection}

Basically, this study is based upon primary data that are collected from SMEs and the respondents have been taken in the survey who is directly associated and connected with the SMEs that are taken as a sample of the SME sector of Cumilla district (as the study is based on SME sector of Cumilla, the primary data is collected from the SME respondents of the study area). The survey is carried out through a structured questionnaire. The study used a simple random sampling procedure to collect data from SME respondents. The following SME respondents are surveyed: Retail Store (except Grocery \& Pharmacy), Poultry, Dairy, Fisheries, Agribusiness, Bakery, ICTbased training center, Cyber Cafe, Dry Food Processing Factory, Mobile Phone Accessories Shop, Crockeries Shop, Hardware Store, Cloth Store, Jewelry Business, Khadi Industries (Lvw` wkí), Finance, Construction, Wooden Furniture Store, Printing \& Packaging, Tourism, Restaurant etc. (Bangladesh Bank Information on SME activities) $\left[{ }^{3}\right]$.

Following the Cochran's Formula of sample size determination for unknown population, it is found that minimum of 384 sample needs to be collected. Due to prolonged lockdown and restriction on movement sample size was reduced to 220 SMEs. The data has been collected from 13 upazilas of Cumilla District at the month of at March and April, 2021 and used in this study to fulfill the designated objectives.

\subsection{Data Collection Zone in Accordance to Upazilas.}

The number of Upazilas surveyed is listed and shown in the following Table 1 with their corresponding frequency and percentage.

Table-1: Location of the SMEs in Upazilas

\begin{tabular}{|l|l|l|l|}
\hline Upazilas & Frequency & Percent & $\begin{array}{l}\text { Cumulative } \\
\text { Percent }\end{array}$ \\
\hline Barura & 16 & 7.3 & 7.3 \\
\hline Brahmanpara & 15 & 6.8 & 14.1 \\
\hline Burichong & 17 & 7.7 & 21.8 \\
\hline $\begin{array}{l}\text { Cumilla } \\
\text { Sadar }\end{array}$ & 18 & 8.2 & 30.0 \\
\hline $\begin{array}{l}\text { Cumilla } \\
\text { Sadar South }\end{array}$ & 22 & 10.0 & 40.0 \\
\hline Chandina & 16 & 7.3 & 47.3 \\
\hline Chauddagram & 16 & 7.3 & 54.5 \\
\hline Daudkandi & 16 & 7.3 & 61.8 \\
\hline Debidwar & 16 & 7.3 & 69.1 \\
\hline Laksam & 16 & 7.3 & 76.4 \\
\hline Lalmai & 17 & 7.7 & 84.1 \\
\hline Muradnagar & 16 & 7.3 & 91.4 \\
\hline Nangalkot & 19 & 8.6 & 100.0 \\
\hline Total & $\mathbf{2 2 0}$ & $\mathbf{1 0 0 . 0}$ & \\
\hline
\end{tabular}

\subsection{Analytical Design}

This study uses several statistical techniques and econometric tools to analyze and present the estimated result of the study. Some forms of mean, standard deviation, percentage, frequency, Cumulative percent, and maximum-minimum value of the different explanatory variables are used for understanding the description of the variables.

The study uses the binary logistic regression model to analyze and continue functioning as well and the adaptation strategy of the SMEs due to the outbreak of Covid-19. Following the working model of Nguyen et al., (2021), three possible adaptation strategies [No Action Taken (NAT), Operation Cost Cut (OCC), \& Staff Cut (SC)] of the SMEs are taken into consideration as dependent variables given the values of the several explanatory variables to find out the way of adaptation of the disturbances that arise due to the Covid-19 outbreak.

To analyze these three adaptation strategies, it is sensible in this stage to assume that,

No Action Taken (NAT) $=1$ (if 'Yes')

No Action Taken (NAT) $=0$ (if 'No')

Operation Cost Cut (OCC) $=1$ (if 'Yes')

Operation Cost Cut (OCC) $=0$ (if 'No')

Staff Cut (SC) = 1 (if 'Yes') 
Rashed Ahmed et al., Saudi J Bus Manag Stud, Jan, 2022; 7(1): 1-10

Staff Cut (SC) $\quad=0$ (if 'No')

The assumption of Logit model is that probability distribution of $u_{\mathrm{i}}$ follows the logistic probability distribution (Gujarati, 2015). Assuming $P$, the probability of Adaptation Strategies is 'Yes': the theoretical logistic regression model now can be written as;

$$
L_{i}=\log \left(\frac{P}{1-P}\right)=\beta_{0}+\beta_{1} A s L+\beta_{2} L a C r+\beta_{3} D e c R+\beta_{4} D e c C R+\beta_{5} D t R+\beta_{6} D E R+u_{i}
$$

Table-2: Measurement of the Explanatory Variables

\begin{tabular}{|l|l|l|}
\hline Variable Indicator & Variable Name & Variable Type \\
\hline$A s L$ & Asset Level of the SMEs & $\begin{array}{l}\text { Continuous \& } \\
\text { Category }\end{array}$ \\
\hline$L a C r$ & Labor Cut Rate & $\begin{array}{l}\text { Category \& } \\
\text { Percentage }\end{array}$ \\
\hline$D e c R$ & Decrease rate of Revenue & $\begin{array}{l}\text { Category \& } \\
\text { Percentage }\end{array}$ \\
\hline$D e c C R$ & Decrease rate of Cash Reserve & $\begin{array}{l}\text { Category \& } \\
\text { Percentage }\end{array}$ \\
\hline$D t R$ & $\begin{array}{l}\text { Cays to Realize the impact of } \\
\text { Covid-19 }\end{array}$ & Continuous \\
\hline$D E R$ & Debt-Equity Ratio & Continuous \\
\hline
\end{tabular}

Then, descriptive statistics results and the open-ended responses collected from the respondents using ranking order were used to realize the factors that cause impediments of SME sectors since the outbreak of Covid-19. Finally, from the estimated results of the study, some policy recommendations will be provided.

\section{DESCRIPTIVE STATISTICS OF THE STUDY}

The present section provides a short description of the comprehensive objective of the study. To analyze the comprehensive objective of the study, it is necessary to give a sketch of the respondents' interactive information that best attires the variables used in this study. The facts and figures provided in this part are using the primary data collected from the respondents to spectacle their contemporary situation in the SME sector. Several statistical tools such as frequency distribution, percentage, mean, standard deviation, etc. are presented in tabular and graphical forms to visualize the information.

\subsection{Characteristic Features of the Respondents}

This section presents some of the demographic, socio-economic, and SME related characteristics of the respondents which needs to be discussed first before going to start our specific objectives of the study as it is believed that these factors have an obvious impact on the SME business (Following research work of Nguyen, et al., 2021). To explain the complications arising in the SME sector due to Covid-19 and to provide some explanation \& ways to overcome it, the following subsection is used to state the information about the respondents who are related to SMEs directly.

\subsubsection{Age Group of the Respondents}

To report about the SME functioning people who have been running their business \& operation and related to the SME sector taken as respondents it was predetermined that they should be at least 18 years old and their age distribution is mentioned in Table 3 to present their demographic characteristics.

Table-3: Age Group of the Respondents

\begin{tabular}{|l|l|l|l|}
\hline Age (in years) & Frequency & Percent & Cumulative Percent \\
\hline $18-25$ & 28 & 12.7 & 12.7 \\
\hline $26-35$ & 100 & 45.5 & 58.2 \\
\hline $36-45$ & 62 & 28.2 & 86.4 \\
\hline $46-55$ & 11 & 5.0 & 91.4 \\
\hline $56-65$ & 18 & 8.2 & 99.5 \\
\hline above 65 & 1 & 0.5 & 100.0 \\
\hline Total & $\mathbf{2 2 0}$ & $\mathbf{1 0 0 . 0}$ & \\
\hline \multicolumn{4}{|l|}{ Source: Authors' Calculation based on Field Survey 2021 } \\
\hline
\end{tabular}

From Table 3, it is clear that the highest number of SMEs (100 SMEs among 220 partaking 45.5 percent) are associated with the age category of 26 to 35 years people which can be thought as that young people 
Rashed Ahmed et al., Saudi J Bus Manag Stud, Jan, 2022; 7(1): 1-10

are more interested to do SME business rather than other age categories. Again, the second-largest percentage fall in the age category between 36 to 45 year having 28.2 percent of the total respondents. It is also observed from the cumulative rate that 86.4 percent of respondents are in ages between 18 to 45 years.

\subsubsection{Gender Distribution of the Respondents}

The gender distribution of respondents shows that the association rate of females in the SME sector is low about male and it is seen from the Table 4 that only 1.8 percent female is associated with the SME sector where the male respondents conform the remaining 98.2 percent.

Table-4: Gender Distribution of the Respondents

\begin{tabular}{|l|l|l|l|}
\hline & Frequency & Percent & Cumulative Percent \\
\hline Female & 4 & 1.8 & 1.8 \\
\hline Male & 216 & 98.2 & 100.0 \\
\hline Total & 220 & 100.0 & \\
\hline Source: Authors' Calculation based on Field Survey 2021 \\
\hline
\end{tabular}

\subsubsection{Level of Education of the Respondents}

The survey shows that there is a variety in the education level of the respondents. Table 5 shows that the majority of the respondents 44.5 percent of this survey have higher secondary school certificates or college degrees. A large part of the SMEs in Cumilla district is handled by the people with higher secondary school certificates.

Table-5: Level of Education of the Respondents (in years of schooling)

\begin{tabular}{|l|l|l|l|}
\hline & Frequency & Percent & Cumulative Percent \\
\hline No Education (0) & 2 & 0.9 & 0.9 \\
\hline Primary school education (1-5) & 11 & 5.0 & 5.9 \\
\hline Secondary school education (6-10) & 40 & 18.2 & 24.1 \\
\hline Higher secondary education (11-12) & 98 & 44.5 & 68.6 \\
\hline Bachelors' Degree (13-16) & 42 & 19.1 & 87.7 \\
\hline Masters' Degree (17-18) & 27 & 12.3 & 100.0 \\
\hline Total Source: Authors' Calculation based on Field Survey 2021 \\
\hline \multicolumn{4}{|l}{} \\
\hline
\end{tabular}

The second-largest portion of respondents of this survey has bachelor degree certification which lodges 19.1 percent (with a frequency of 42) of the total. Respondents with master's degrees with 27 frequency have less involvement in the SME sector. Respondents with primary education (5 percent) and no education category ( 0.9 percent) have less involvement in the SME sector in Cumilla.

\subsection{Descriptive Statistics of the Surveyed SMEs}

This section presents diverse sorts of facts \& figures regarding the surveyed SMEs which shows the nature and scopes of the SMEs of the study area. The number of employees, asset level, running years, realization time to understand the impacts of Covid-19 on their SME, their revenue earning pattern during Covid-19 etc. are presented following to draw an overall scenario of the SME sector of the study area.

\subsubsection{Scale of SMEs in terms of the Number of Employees}

This survey is carried out by dividing SMEs into several patterns in terms of the employees. It is observed from the stated information (Table 6) of the respondent that most of the SMEs (195 SMEs of 220) are Micro SME (managed by not more than 5 employees in their operation) which occupies 88.6 percent of SMEs and thus represents the majority percent of the three categories. It is found that 10.9 percent of SMEs were small in size and the rest 0.5 percent were medium in size. The study didn't find any SMEs with over 100 employees in the survey period. Thus, the results of the study results reveal that micro SMEs block up the most significant part of the stated sector.

Table-6: Scale of SMEs in Terms of Employees

\begin{tabular}{|l|l|l|l|}
\hline & Frequency & Percent & Cumulative Percent \\
\hline Micro SME (1-5) & 195 & 88.6 & 88.6 \\
\hline Small SME (6-30) & 24 & 10.9 & 99.5 \\
\hline Medium SME (31-100) & 1 & 0.5 & 100.0 \\
\hline Total & 220 & 100.0 & \\
\hline \multicolumn{2}{|l|}{ Source: Authors' Calculation based on Field Survey 2021 } \\
\hline
\end{tabular}


Rashed Ahmed et al., Saudi J Bus Manag Stud, Jan, 2022; 7(1): 1-10

\subsubsection{Size of the SME in terms of asset}

The asset level of any business sector is an important parameter to scale it and it also determines how strong it is in its operation. Again, a good level of asset also decreases its probability of failure and reduces vulnerability to exposure in an uncertain situation like Covid-19. Table 7 shows information variety of SMEs in terms of asset level of the SMEs which shows a regular pattern of the asset level. The two largest categories found here are Small SME and Large SME partaking 35.9 percent and 31.4 percent as well. The Medium SME category makes 24.1 percent share of the SME sector where the remaining 8.6 percent is filled by Micro SME.

Table-7: Size of the SME in terms of Asset (in Tk.)

\begin{tabular}{|l|l|l|l|}
\hline & Frequency & Percent & Cumulative Percent \\
\hline Micro SME (Less than 100,000) & 19 & 8.6 & 8.6 \\
\hline Small SME (100,000 - 500,000) & 79 & 35.9 & 44.5 \\
\hline Medium SME (500,000 - 1,000,000) & 53 & 24.1 & 68.6 \\
\hline Large SME (above 1,000,000) & 69 & 31.4 & 100.0 \\
\hline Total Source: Authors' Calculation based on Field Survey 2021 \\
\hline \multicolumn{4}{|l}{} \\
\hline
\end{tabular}

\subsubsection{Years of SMEs operation}

This section shows the operation time of the SMEs which is measured in years and represents the experience period of the respective SMEs in question. From Table 8 it is seen that the maximum number of
SMEs (70 SMEs which is $31.8 \%$ ) have 5 to 10 years of operation experience. The second-largest $(26.8 \%)$ and third category $(15.9 \%)$ have 2 to 5 years and more than 20 years of running experience.

Table-8: Years of SMEs operation

\begin{tabular}{|l|l|l|l|}
\hline & Frequency & Percent & Cumulative Percent \\
\hline Less than 2 years & 23 & 10.5 & 10.5 \\
\hline 2 to 5 years & 59 & 26.8 & 37.3 \\
\hline 5 to 10 years & 70 & 31.8 & 69.1 \\
\hline 11 to 15 years & 17 & 7.7 & 76.8 \\
\hline 16 to 20 years & 16 & 7.3 & 84.1 \\
\hline More than 20 years & 35 & 15.9 & 100.0 \\
\hline Total & $\mathbf{2 2 0}$ & $\mathbf{1 0 0 . 0}$ & \\
\hline \multicolumn{4}{|l|}{ Source: Authors' Calculation based on Field Survey 2021 } \\
\hline
\end{tabular}

\subsubsection{Did the SMEs Faces Decline in Revenue?}

To perceive the impact of covid-19 on the SME sector, it is important to know the revenue status: either it declining or not for those SMEs since their realization time. This study found that most of the SMEs had faced a declining rate of revenue. Table 9 shows that 93.6 percent of SMEs faced a decline in revenue earnings while the rest $6.4 \%$ are not.

Table-9: Decline in Revenue Due to Covid-19

\begin{tabular}{|l|l|l|l|}
\hline Decline in Revenue & Frequency & Percent & Cumulative Percent \\
\hline Yes & 206 & 93.6 & 93.6 \\
\hline No & 14 & 6.4 & 100.0 \\
\hline Total & $\mathbf{2 2 0}$ & $\mathbf{1 0 0 . 0}$ & \\
\hline \multicolumn{4}{|c|}{ Source: Authors' Calculation based on Field Survey 2021 } \\
\hline
\end{tabular}

\subsection{Analysis of the Key Variables used in the Model}

The study is based on primary data that are collected from the respondents who are engaged in the SME sector directly. These information's are edited, sorted, and coded to make them suitable to analyze and in so doing to meet the specific objectives of the study. These analyses are carried out to see the impact of Covid-19 on SME by postulating three core assessments
(No Action Taken, Operation Cost Cut, and Staff Cut) taken in the SME sector as a whole. These actions are not similar among all the SME's and it is seen that there are significant differences in their decisions and strategies taken to mitigate the impact of Covid-19. The Variables used in the Binary logit model are presented in Table 10 with their essential presences for 220 valid responses. 
Rashed Ahmed et al., Saudi J Bus Manag Stud, Jan, 2022; 7(1): 1-10

Table-10: Descriptive Statistics of the Key Variables

\begin{tabular}{|c|c|c|c|c|}
\hline Variable & \multicolumn{2}{|l|}{ Category } & Frequency & Percent \\
\hline \multirow{5}{*}{ Asset Level of the SMEs $(A s L)$} & \multicolumn{2}{|l|}{ Micro SME } & 19 & 8.6 \\
\hline & \multicolumn{2}{|l|}{ Small SME } & 79 & 35.9 \\
\hline & \multicolumn{2}{|c|}{ Medium SME } & 53 & 24.1 \\
\hline & \multicolumn{2}{|c|}{ Large SME } & 69 & 31.4 \\
\hline & \multicolumn{2}{|l|}{ Total } & 220 & 100 \\
\hline \multirow{6}{*}{ Labor Cut Rate ( $\mathrm{LaCr}$ ) } & \multicolumn{2}{|l|}{$0 \%$} & 167 & 75.9 \\
\hline & \multicolumn{2}{|l|}{ below $20 \%$} & 8 & 3.6 \\
\hline & \multicolumn{2}{|l|}{$21-40 \%$} & 28 & 12.7 \\
\hline & \multicolumn{2}{|l|}{$41-60 \%$} & 14 & 6.4 \\
\hline & \multicolumn{2}{|l|}{$61-80 \%$} & 3 & 1.4 \\
\hline & \multicolumn{2}{|l|}{ Total } & 220 & 100 \\
\hline \multirow{7}{*}{ Decrease rate of Revenue (DecR) } & \multicolumn{2}{|l|}{$0 \%$} & 15 & 6.8 \\
\hline & \multicolumn{2}{|l|}{ below $20 \%$} & 21 & 9.5 \\
\hline & \multicolumn{2}{|l|}{$21-40 \%$} & 55 & 25.0 \\
\hline & \multicolumn{2}{|l|}{$41-60 \%$} & 78 & 35.5 \\
\hline & \multicolumn{2}{|l|}{$61-80 \%$} & 49 & 22.3 \\
\hline & \multicolumn{2}{|l|}{ above $80 \%$} & 2 & 0.9 \\
\hline & \multicolumn{2}{|l|}{ Total } & 220 & 100 \\
\hline \multirow{7}{*}{ Decrease rate of Cash Reserve (DecCR) } & \multicolumn{2}{|l|}{$0 \%$} & 68 & 30.9 \\
\hline & \multicolumn{2}{|l|}{ below $20 \%$} & 65 & 29.5 \\
\hline & \multicolumn{2}{|l|}{$21-40 \%$} & 28 & 12.7 \\
\hline & \multicolumn{2}{|l|}{$41-60 \%$} & 27 & 12.3 \\
\hline & \multicolumn{2}{|l|}{$61-80 \%$} & 13 & 5.9 \\
\hline & \multicolumn{2}{|l|}{ above $80 \%$} & 19 & 8.6 \\
\hline & \multicolumn{2}{|l|}{ Total } & 220 & 100 \\
\hline & Minimum & Maximum & Mean & Std. Deviation \\
\hline Days to Realize the impact of Covid-19 (DtR) & 0 & 190 & 30.32 & 25.498 \\
\hline Debt-Equity Ratio $(D E R)$ & -2.67 & 3.50 & 0.3531 & 0.66111 \\
\hline
\end{tabular}

\section{ESTIMATION AND DISCUSSION OF RESULTS}

This section is developed for presenting the econometric results of the study which is the estimation of binary logistic outcome for the three possible strategies of the SMEs to cope with the Covid-19 situation. Then, some descriptive results are also presented which comes directly from the respondents and finally, policy recommendations are drawn for better management of the SMEs.

\subsection{Estimation of Binary Logit Model}

The binary logistic model estimation is carried out in this study to assess the SMEs' Covid-19 adaptation strategies of the SMEs on the likelihood that the SMEs would report that they had tried to cope up by employing three possible strategies (No Action Taken, Operation Cost Cut, \& Staff Cut) against to six explanatory variables. The estimated results are shown in the following tables.

Table-11: Model Summary for the Strategy of 'No Action Taken'

\begin{tabular}{|c|c|c|c|c|c|c|c|c|}
\hline \multicolumn{3}{|c|}{-2 Log likelihood } & \multicolumn{3}{|c|}{ Cox \& Snell R Square } & \multicolumn{3}{|c|}{ Nagelkerke R Square } \\
\hline \multicolumn{3}{|c|}{210.607} & \multicolumn{3}{|c|}{.308} & \multicolumn{3}{|c|}{.419} \\
\hline & \multirow[t]{2}{*}{ B } & \multirow[t]{2}{*}{ S.E. } & \multirow[t]{2}{*}{ Wald } & \multirow[t]{2}{*}{ df } & \multirow[t]{2}{*}{ Sig. } & \multirow[t]{2}{*}{ OR } & \multicolumn{2}{|c|}{ 95\% C.I. for OR } \\
\hline & & & & & & & Lower & Upper \\
\hline$A s L$ & $-.548 * * *$ & .184 & 8.874 & 1 & .003 & .578 & .403 & .829 \\
\hline $\mathrm{LaCr}$ & $-1.414 * * *$ & .231 & 37.375 & 1 & .000 & .243 & .155 & .383 \\
\hline DecR & -.030 & .163 & .033 & 1 & .855 & .971 & .705 & 1.336 \\
\hline $\operatorname{Dec} C R$ & .025 & .120 & .045 & 1 & .832 & 1.026 & .811 & 1.297 \\
\hline$D t R$ & -.001 & .007 & .025 & 1 & .875 & .999 & .986 & 1.012 \\
\hline$D E R$ & -.340 & .266 & 1.642 & 1 & .200 & .712 & .423 & 1.197 \\
\hline Constant & 2.957 & .729 & 16.459 & 1 & .000 & 19.234 & & \\
\hline
\end{tabular}


Rashed Ahmed et al., Saudi J Bus Manag Stud, Jan, 2022; 7(1): 1-10

The first model is developed on the 'No Action taken' strategy of the SMEs and the model as a whole reflects statistically significant $\chi^{2}(6, N=220)=80.99, p$ $<0.001$, indicating that the model is capable of differentiating between SMEs who reported and did not report on 'No Action Taken'. According to the model summary and observing the value of Cox and Snell $R$ square and Nagelkerke $R$ square, it can be said that the dependent variable is explained between $30.8 \%$ and $41.9 \%$ as well and correctly classified for $77.3 \%$ of cases.

Table 11 shows that the Asset Level (AsL) of the SMEs and Labor Cut Rate $(\mathrm{LaCr})$ variables are statistically significant. The $A s L$ variable shows a negative Beta-coefficient (-0.548) which means if the asset of the SMEs increases then the probability of the strategy 'No Action Taken' decreases. The odds ratio of $A s L$ variable indicates that for every additional unit of asset, SMEs were 0.58 times less likely to report on 'No Action Taken'. The variable 'Labor Cut Rate' also shows a negative sign $(-1.414)$ which indicates that with a decrease in one unit of labor then the probability of the strategy 'No Action Taken' reduces: thus reflecting some action happening. The corresponding odds ratio of $\mathrm{LaCr}$ means for one unit of labor cut in the SME, the 'No Action Taken' strategy was less likely to be happening by 0.24 times, in ceteris paribus.

Table-12: Model Summary for the Strategy of 'Operation Cost Cut'

\begin{tabular}{|c|c|c|c|c|c|c|c|c|}
\hline \multicolumn{2}{|c|}{-2 Log likelihood } & \multicolumn{3}{|c|}{ Cox \& Snell R Square } & \multicolumn{4}{|c|}{ Nagelkerke R Square } \\
\hline \multicolumn{2}{|c|}{236.274} & \multicolumn{3}{|c|}{.085} & \multicolumn{4}{|c|}{.124} \\
\hline & \multirow[t]{2}{*}{ B } & \multirow[t]{2}{*}{ S.E. } & \multirow[t]{2}{*}{ Wald } & \multirow[t]{2}{*}{ df } & \multirow[t]{2}{*}{ Sig. } & \multirow[t]{2}{*}{$\overline{\text { OR }}$} & \multicolumn{2}{|c|}{$95 \%$ C.I. for OR } \\
\hline & & & & & & & Lower & Upper \\
\hline AsL & $.573 * * *$ & .178 & 10.405 & 1 & .001 & 1.773 & 1.252 & 2.511 \\
\hline $\mathrm{LaCr}$ & .235 & .147 & 2.553 & 1 & .110 & 1.265 & .948 & 1.688 \\
\hline DecR & .171 & .157 & 1.191 & 1 & .275 & 1.187 & .873 & 1.614 \\
\hline DecCR & -.181 & .119 & 2.301 & 1 & .129 & .835 & .661 & 1.054 \\
\hline$\overline{D t R}$ & -.005 & .007 & .483 & 1 & .487 & .995 & .982 & 1.009 \\
\hline$D E R$ & -.154 & .251 & .378 & 1 & .539 & .857 & .524 & 1.401 \\
\hline Constant & -2.797 & .688 & 16.541 & 1 & .000 & .061 & & \\
\hline
\end{tabular}

'Operation Cost Cut' strategy of the SMEs is used to build up the second model. With $\chi^{2}(6, N=220)$ $=19.561, p<.001$, the model is statistically significant and thus indicates that the model is effectively separates SMEs who reported and did not report on 'Operation Cost Cut' strategy. Considering the explanatory variables used in the model, it is explained between 8.5\% (Cox and Snell R square) and 12.4\% (Nagelkerke
$\mathrm{R}$ square) of the variance of Operation Cost Cut, and $75 \%$ cases are classified correctly in the estimation.

The only statistically significant variable in the estimated model is Asset Level ( $A s L$ ) indicating a positive coefficient (0.573) and the odds ratio of 1.773 representing that SMEs who had increasing asset level were over 1.77 times more likely to report yes on Operation Cost Cut than the SMEs with low asset level, controlling other factors in the model.

Table-13: Model Summary for the Strategy of 'Staff Cut'

\begin{tabular}{|c|c|c|c|c|c|c|c|c|}
\hline \multicolumn{3}{|c|}{-2 Log likelihood } & \multicolumn{3}{|c|}{ Cox \& Snell R Square } & \multicolumn{3}{|c|}{ Nagelkerke R Square } \\
\hline \multicolumn{3}{|c|}{66.508} & \multicolumn{3}{|c|}{.521} & \multicolumn{3}{|c|}{.806} \\
\hline & \multirow[t]{2}{*}{ B } & \multirow[t]{2}{*}{ S.E. } & \multirow[t]{2}{*}{ Wald } & \multirow[t]{2}{*}{ df } & \multirow[t]{2}{*}{ Sig. } & \multirow[t]{2}{*}{ OR } & \multicolumn{2}{|c|}{ 95\% C.I. for OR } \\
\hline & & & & & & & Lower & Upper \\
\hline AsL & $.979 * *$ & .453 & 4.670 & 1 & .031 & 2.663 & 1.095 & 6.473 \\
\hline $\mathrm{LaCr}$ & $3.029 * * *$ & .450 & 45.323 & 1 & .000 & 20.673 & 8.560 & 49.929 \\
\hline DecR & -.242 & .341 & .504 & 1 & .478 & .785 & .402 & 1.532 \\
\hline $\operatorname{Dec} C R$ & .113 & .237 & .227 & 1 & .634 & 1.120 & .703 & 1.783 \\
\hline$D t R$ & .011 & .011 & .992 & 1 & .319 & 1.011 & .990 & 1.033 \\
\hline DER & .527 & .464 & 1.289 & 1 & .256 & 1.694 & .682 & 4.210 \\
\hline Constant & -7.001 & 1.847 & 14.374 & 1 & .000 & .001 & & \\
\hline
\end{tabular}

The model about 'Staff Cut' including all explanatory variables was statistically significant, $\chi^{2}(6$, $N=220)=161.735, p<.001$, showing that the model can distinguish between SMEs who reported and did not report on the 'Staff Cut' strategy. The overall model is explained between $52.1 \%$ (Cox and Snell $\mathrm{R}$ square) and $80.6 \%$ (Nagelkerke $\mathrm{R}$ square) of the variance of Staff Cut strategy and the whole model is correctly classified for $93.6 \%$ of cases. 
Rashed Ahmed et al., Saudi J Bus Manag Stud, Jan, 2022; 7(1): 1-10

It is seen from Table 13 that Asset Level $(A s L)$ and Labor cut Rate $(\mathrm{LaCr})$ variables are significant at $95 \%$ and $99 \%$ confidence levels. Asset Level has a positive (0.979) coefficient with an odds ratio of 2.663 mentioning that SMEs with increasing asset level more likely to report that their probability to Staff Cut rises 2.66 times than SMEs with decreasing asset level. It may happen because the SMEs can manage to run their operation at a minimum scale, a measure of Covid-19 adaptation and could survive in the market. The positive coefficient (3.029) of Labor cut Rate $(\mathrm{LaCr})$ predictor indicates that if the labor force is cut by 1 unit then the answer to Staff Cut goes to probability to 'Yes': that means staff was cutting. The odds ratio of the corresponding variable 20.67 shows that the predictor is the strongest in the model. 6.2 Analysis on the Constraints faced by the SMEs

This section is developed to rank the major constraints that have been confronted by the SMEs severely since the outbreak of Covid-19. Kendall's Coefficient of Concordance is used in this study to rank and analyze the conformity of the constraints faced by the SMEs of the study area. The constraints faced by the SMEs in this study are listed in Table 14 and ranked on the basis of their mean score.

Table-14: Analysis of Constraints for the Sample SMEs and their Rankings

\begin{tabular}{|c|c|c|}
\hline \multicolumn{3}{|l|}{$\begin{array}{l}\text { Kendall's W=0.648***; } \mathrm{Chi}^{2}=854.862 ; \\
\text { Asymptotic Significance }=0.000 ; \text { Sample Size }=220\end{array}$} \\
\hline Constraints & Mean Score & Rank \\
\hline Decrease in revenue earnings & 1.23 & 1 \\
\hline Gradual increase of the price of necessary raw materials & 2.55 & 2 \\
\hline Dependency on bank loan rises & 3.41 & 3 \\
\hline Enlargement of debt-equity ratio & 4.19 & 4 \\
\hline Lack of customers & 4.90 & 5 \\
\hline Credit facility decreases & 5.48 & 6 \\
\hline Facing high level of transportation cost & 6.24 & 7 \\
\hline
\end{tabular}

Table 14 illustrates the constraints ranked as 1 is the topmost problem and 7 is the least possible problem based on the findings of the mean score. Kendall's coefficient of concordance (W) on SMEs constraints indicates that the lowermost mean score is ranked as the most persistent problem while the maximum mean score being the lowest pressing problem. Kendall's W is estimated as 0.648 and reflects statistically significant at $99 \%$ confidence level means that $64.80 \%$ of SMEs are reporting and agreeing with ranking.

\subsection{RESULT DISCUSSIONS}

The estimated results of the different patterns are presented in this section. Several statistical results have already been presented in section five with descriptive-analytical procedures. The binary logistic regression model results shows that Asset Level of the SMEs $(A s L)$ and Labor Cut rate $(\mathrm{LaCr})$ variables have significant importance to make their decision and strategy to adapt with Covid-19 and play an important role in coping with the pandemic. In these three types of strategies (No Action Taken, Operation Cost Cut, \& Staff Cut), Asset Level shows significant influence, and the Labor Cut variable is significant on (No Action Taken \& Staff Cut) decisions as well. Again, significant Kendall's coefficient of concordance (W) conforms that SMEs agree to these constraints that impede the SME sector badly. Thus, from the analysis of the above findings, it can be carefully proclaimed that asset level and labor employed to the SMEs are important factors in the operation. Therefore, vigilant and thoughtful management of SMEs' asset level and labor force are advised to adapt and cope up with the pandemic situation. Finally, the SME respondents were urged not to impose prolonged lockdown and to attain an easy credit facility to survive in the pandemic situation.

\section{SIGNIFICANCE OF THE STUDY}

The study is taken with a keen interest in searching for the possible ways of how to adapting to this pandemic situation with clutching proper precautionary measures. The findings may be essential for the decision-making authority and also for the people engaged in SMEs. The study is worth mentioning from many aspects. Firstly, there is little such research in this arena, particularly in the Cumilla district. Secondly, the findings of the study demonstrate the overall SMEs' existing scenario of the study area with problems and further prospects. The importance of SMEs asset level and labor force initiated in this study as the most important factor. Hence, the projections go on the improvement of asset level of the SMEs and to the labor's promising engagement. Finally, the work would act as a guideline for future predictors and researchers in this link.

\section{ACKNOWLEDGEMENT}

The Corresponding author of the research gratefully acknowledges the financial support from Comilla University, Bangladesh. 


\section{REFERENCES}

- Adian, I., Doumbia, D., Gregory, N., Ragoussis, A., Reddy, A., \& Timmis, J. (2020). Small and Medium Enterprises in the Pandemic Impact, Responses and the Role of Development Finance. World Bank Group, International Finance Corporation.

- Bartik, A. W., Bertrandb, M., Cullenc, Z., Glaeserd, E. L., Lucac, M., \& Stantonc, C. (2020). The impact of COVID-19 on small business outcomes and expectations. retrieved from www.pnas.org/cgi/doi/10.1073/pnas.2006991117

- Coronavirus COVID-19 Dashboard, 2020. Retrieved from http://dashboard.dghs.gov.bd/webportal/pages/covi d19.php

- Donthu, N., \& Gustafsson, A. (2020). Effects of COVID-19 on business and research. Journal of Business Research, 117; 284-289.

- Gujarati, D. (2015). Econometrics by Example. Palgrave.

- Kirk, C. P., \& Rifkin, L. S. (2020). I'll trade you diamonds for toilet paper: Consumer reacting, coping and adapting behaviors in the COVID-19 pandemic. Journal of Business Research, 117; 124 131.

- (Light-Castle Partners \& Sheba.xyz, 2020). https://www.lightcastlebd.com/insights/2020/05/09/ covid-19-impact-on-the-sme-sector-of-bangladesh. (MMWU, $07 \quad$ Sep., 2020$)$ https://www.who.int/docs/defaultsource/searo/bangladesh/covid-19-whobangladesh-situation-reports/who-covid-19-update28-20200907.pdf?sfvrsn=108ef905_2

- Nguyen, H. H., Ngo, V. M., \& Tran, A. N. T. (2021). Financial performances, entrepreneurial factors and coping strategy to survive in the COVID-19 pandemic: case of Vietnam., Research in International Business and Finance. https://doi.org/10.1016/j.ribaf.2021.101380.

- Bangladesh Bank report on SME activities. Retrieved from https://bb.org.bd/openpdf.php

- Seetharaman, P. (2020). Business models shifts: Impact of Covid-19. International Journal of Information Management., https://doi.org/10.1016/j.ijinfomgt.2020.102173.

- Sheth, J. (2020). Impact of Covid-19 on consumer behavior: Will the old habits return or die? Journal of Business Research. https://doi.org/10.1016/j.jbusres.2020.05.059. 